\title{
Classical optics in France: introduction
}

\author{
Yannick Berthoumieu, ${ }^{1}$ Christine Fernandez-Maloigne, ${ }^{2}$ David Alleysson, ${ }^{3}$ Sylvain Gigan, ${ }^{4}$ \\ and Olivier Haeberlé ${ }^{5}$ \\ ${ }^{1}$ Univ. Bordeaux, CNRS, Bordeaux INP, France \\ ${ }^{2}$ University of Poitiers, Poitiers, France \\ ${ }^{3}$ CNRS/University Grenoble Alpes, Grenoble, France \\ ${ }^{4}$ Sorbonne Université, Paris, France \\ ${ }^{5}$ Université de Haute-Alsace, Mulhouse, France
}

This special issue of the Journal of the Optical Society of America A (JOSA A) is devoted to the wide array of French researchers from universities and state research organisms, offering them the opportunity to share and showcase their current research in the fields of optics and imaging sciences to the global community. (C) 2019 Optical Society of America

France has strong a foundation in optics, image science, and vision, being the birthplace of Joseph Fourier and Augustin Fresnel, founders of modern optics, whose works, among an abundance of pioneers in the field, have led the way for today's researchers.

In 1794, the French engineer Claude Chappe realized the first system of optical transmission (telegraphy by semaphore) between Paris and Lille. Early in the 19th century, Joseph Nicéphore Niépce succeeded first in preserving an image due to the action of light, leading to famous inventions by the brothers Louis and Auguste Lumière. In parallel, Gabriel Lippmann was awarded the Nobel Prize in Physics in 1908 for his method of reproducing colors in photography, based on the phenomenon of interference. Charles Fabry almost exclusively devoted his work to optics, especially to interferometry, spectroscopy, and photometry. In the 1950s, pioneering work by Georges Nomarski allowed efficient differential interference contrast (DIC) microscopy. The invention of the laser necessitated the development of optical pumping, proposed by Alfred Kastler, Nobel Prize in Physics in 1966, with continuous development toward always shorter and more powerful impulsions, the focus of the work of Gérard Mourou, Nobel Prize in Physics in 2018.

The advent of digital computation brought about the success of advanced processing, leading to significant progresses in the world of optical information processing, spectral imaging, and optical measurement. Following pioneers such as Georges Matheron and Jean Serra, other researchers like Olivier Faugeras and Stéphane Mallat have added their names to the history of so-called "artificial vision."

Nowadays, the fields of optics and imaging sciences are still booming in France, being particularly active in domains such as computational optics, adaptive optics, ultrafast optics, superres- olution imaging, and ultrahigh-performance optics. France also boasts a very active and high-tech industrial base, with research and development activities involving partners from around the world. From the country's history in optics and its current strength in this field, this special issue is designed to illustrate the large panel of relevant French researchers from universities and state research organisms, offering them the opportunity to share and showcase their current research to the global community.

On behalf of our community we wish to thank the Editorial Board for providing us with this opportunity, the reviewers for their generous assistance, and the staff at OSA for their patient and professional support. 